\title{
Microrganismos Eficazes na Produção da Cultura do Feijoeiro
}

\author{
Pedro Ronzelli Júnior ${ }^{* 1}$, Marly Terezinha Coradassi Buff ${ }^{2}$ \& Henrique Soares Koehler ${ }^{3}$ \\ ${ }^{I}$ Bolsista do CNPq, Engenheiro. Agrônomo, Doutor, Professor Adjunto IV do Departamento de Fitotecnia e \\ Fitossanitarismo da UFPR, Caixa Postal 19061, CEP 81531-990, Curitiba, PR - Brasil. ${ }^{2}$ Engenheira Agrônoma, \\ Bolsista do CNPq. ${ }^{3}$ Engenheiro Florestal, Mestre, Professor Adjunto IV do Departamento de Fitotecnia e \\ Fitossanitarismo da UFPR, Curitba - PR - Brasil.
}

\begin{abstract}
Considering the importance of dry beans as a food source and how essential is to improve its production, a two years, experiments in 1995/96, and 1996/97, were carried out to evaluate the efficient microorganism (EM) fertilizer action in comparison to the NPK traditional chemical fertilization. The experiments were done at Federal University of Paraná Experiment Station of Canguiri, in Pinhais, PR, on a Latossolo Vermelho Amarelo Álico soil, prepared on the conventional way, in an uniform area. The EM was tested in six dilution, 1:250, 1:500, 1:750, 1:1.000, 1:1250, and 1:1.500. The product was always applied on the leaves seven times through the cicle, for all the dilution, four in week interval, two in fifteen days interval and one in month interval. The NPK fertilization was defined by the soil analysis. It was applied together with the seeds and complemented by a $N$ cover fertilization. A randomized complete block design with four replications was used. The variables evaluated, just in the first year, were the morphological characteristics: plant stature, stem diameter, node number and leaf number, and in both years, the initial and final stand, the yield components and yield. The results showed that the EM can not be recommended as a substitute to the NPK chemical fertilization and was not found any evidence to indicate one of the dilution to be used.
\end{abstract}

Key words: Phaseolus vulgaris, efficient microorganism, yield

\section{INTRODUÇÃO}

O feijão é fabácea (leguminosa) de consumo generalizado pela população brasileira. Para os seguimentos de baixa renda se constitui na principal fonte de proteínas. Além disso é o principal gerador de renda para representativo número de agricultores. Apesar das oscilações, estima-se o consumo em mais de $18 \mathrm{~kg}$.habitante. $\mathrm{ano}^{-1}$, sendo cultivado em mais de cinco milhões de hectares com produção de cerca de três milhões de toneladas e produtividade pouco superior a seiscentos $\mathrm{kg} \cdot \mathrm{ha}^{-}$ ${ }^{1}$ (IBGE, 1996; Yokoyama et al., 1996).

A importância econômica da cultura para o Brasil pode ser facilmente verificada pois as informações dos levantamentos estatísticos apresentam o País como o segundo maior produtor mundial de feijão e responsável por quase vinte por cento da produção, sem distinção entre os gêneros Phaseolus e Vigna. Nesse raciocínio o Estado do Paraná tem significativa importância, uma vez que é um dos principais estados produtores de feijão, sendo por muitas vezes o maior produtor brasileiro dessa fabácea (leguminosa) tão importante para a alimentação humana (Demarchi, 1997; IAPAR, 1989; IBGE, 1996).

A produção mundial de feijão além de não ser estável tem como agravante ser baixa quando comparada com a de cereais e ainda o fato de não ter acompanhado a explosão demográfica que vive o mundo (Vogtmann \& Wagner, 1987). Observa-se, cada vez mais, que o aumento da produção, antes obtido por expansão de área, tende a ser obtido por aumentos na produtividade que dependem da adoção de tecnologias que envolvem semeadura dentro de

\footnotetext{
* Autor para correspondência.
} 
períodos mais propícios, utilização de variedades com alto potencial genético, sementes de boa qualidade, população de plantas adequada, recuperação da matéria orgânica do solo, manejo integrado de doenças, pragas e plantas daninhas e, especialmente, da utilização racional dos fertilizantes (IAPAR, 1989).

Os microrganismos eficazes (EM) foram identificados no início dos anos 1980 sendo ainda muito pouco utilizados e conhecidos no Brasil. A maioria dos estudos tem sido realizados no Japão. Pesquisas tem sido feitas comparando a ação fertilizante do produto, bem como sua ação múltipla sobre o solo e as plantas (Fundação Mokiti Okada, s/d; Higa, 1991a; Melloni, 1991). Fazem parte do EM microrganismos que produzem substâncias orgânicas úteis às plantas e que ao mesmo tempo atuam na melhoria das propriedades físicas, químicas e biológicas dos solos. Sugere-se que o EM atua no solo fazendo com que este passe para um estado de fermentação, sobre o nitrogênio interferindo na predominância da forma orgânica, sobre o balanço energético da planta que é favorecido pela redução de gastos no processo de síntese de proteínas, no processo da fotossíntese que é aumentado e sobre a produção e qualidade do produto que são aumentados (Higa, 1991a).

Algumas pesquisas relatadas sugerem que $\mathrm{o}$ tempo necessário para que a utilização do EM produza os efeitos esperados é variável. Há resultados positivos como a elevação do teor de húmus, aumento nos teores de $\mathrm{N}$ total, $\mathrm{P}, \mathrm{K}, \mathrm{Ca}$ e $\mathrm{Mg}$, que culminaram com aumentos na produtividade do amendoim, redução na incidência de doenças com aumento na produtividade do tomateiro, elevação nos teores de vitamina A em cenoura e vitamina $\mathrm{C}$ em acerola, aumento na velocidade de fotossíntese em citrus e aumento da produtividade do arroz (HIGA, 1991b). Experiências com a cultura do feijoeiro sugerem que o EM interferiu no aumento da produtividade (Fundação Mokiti Okada, 1994). Estudo sobre as propriedades sensoriais do produto final feijão, tais como cor, sabor, textura e odor, além do valor nutritivo do alimento mostraram que o EM interfere favoravelmente nessas características (Higa, 1991; Vilhordo, 1988; Vogtmann \& Wagner, 1987).
Os trabalhos com o EM utilizam como ponto de partida a diluição de 1:1.000 do produto comercial (Fundação Mokiti Okada, s.d; Fundação Mokiti Okada, 1994), não havendo qualquer recomendação para a cultura do feijoeiro.

Tem-se o fato que é a inevitável necessidade de produzir mais alimentos para atender a crescente demanda. Como alcançar isso é a questão. A bibliografia sobre a utilização de fertilizantes na cultura do feijoeiro, apesar de extensa não é consistente, desde a revisão feita por Malavolta (1972), até as mais recentes (Moraes, 1988; Oliveira et al., 1996; Thung, 1991), no entanto, permite ter por hipótese que a utilização racional dos fertilizantes, por si só, pode ser fator de aumento na produção e produtividade dos feijoeiros. Isso justifica a necessidade de estudar tipos e quantidades de fertilizantes, sobretudo quando a fonte é natural e as informações não são específicas para a cultura. Assim, o objetivo do presente trabalho foi o de comparar a eficiência da adubação natural com o produto microrganismos eficazes, em relação à adubação química usual, na produtividade do feijoeiro.

\section{MATERIAL E MÉTODOS}

O trabalho experimental foi realizado a campo, nos anos agrícolas 1995/96 e 1996/97, na Estação Experimental do Canguiri, uma das unidades do Centro de Estações Experimentais da Universidade Federal do Paraná (UFPR), em Pinhais, PR. A área, localizada entre as coordenadas de $25^{\circ}$ e $25^{\prime}$ de latitude Sul e $49^{\circ}$ e $14^{\prime}$ de longitude Oeste e altitude entre as cotas de 907 e 945 metros, era uniforme e com declividade média de 6\%. Com base nos estudos de levantamento e reconhecimento dos solos da região, os experimentos foram instalados em solo que se caracteriza como sendo um Latossolo Vermelho Amarelo Álico. Foram coletadas amostras do solo, na faixa de 0 a $20 \mathrm{~cm}$, para análises física e química e os resultados são apresentados no Quadro 1. O clima da região é classificado, segundo Koeppen, como $\mathrm{Cfb}$, subtropical úmido, mesotérmico, verões frescos, geadas severas demasiadamente freqüentes, sem estação seca, 
temperaturas médias máxima de $24^{\circ} \mathrm{C}$ e mínima de $11^{\circ} \mathrm{C}$, precipitação média anual de $1.500 \mathrm{~mm}$ e umidade relativa do ar a ordem de $80 \%$.

A área experimental foi preparada, semelhantemente, nos anos agrícolas 1995/96 e 1996/97. No primeiro ano, em 15 SET 1995, foi feita a aração e duas gradagens niveladoras. Antes da segunda gradagem aplicou-se herbicida com o princípio ativo trifluralin, para o controle das plantas daninhas encontradas, principalmente gramíneas anuais, muito freqüentes na área. Em 19 OUT 1995 foi distribuída e incorporada com enxada silagem de milho nas parcelas que receberiam o EM, na base de 20 tha $^{-1}$, com a finalidade de servir como fonte de matéria orgânica para melhor ação do produto. Em 17 NOV 1995 foram feitos, com enxada, os sulcos para adubação e semeadura manuais. As parcelas a serem adubadas com adubo químico receberam o equivalente a $300 \mathrm{~kg} \cdot \mathrm{ha}^{-1}$ do formulado NPK 430-10, que foi misturado ao solo. Vinte dias após a emergência das plantas, em 13 DEZ 1995, foi feita, nessas parcelas, a adubação em cobertura com $\mathrm{N}$ na proporção de $40 \mathrm{~kg} . \mathrm{ha}^{-1}$, utilizando-se a uréia como fonte. As sementes foram previamente tratadas com fungicida a base de benomil e colocadas no sulco em quantidade suficiente para obter população de aproximadamente trezentas mil plantas por hectare. A emergência da cultura foi uniforme, identificada em 23 NOV 1995 e em
28 NOV 1998 foi feita a contagem da população inicial. Em 30 NOV 1995 foi feita a primeira capina com enxada e a segunda em 22 DEZ 1995. Durante o ciclo foram feitas três aplicações com o fungicida a base da mistura de clorotalonil, $500 \mathrm{~g} \cdot \mathrm{kg}^{-1}+$ tiofanato metílico, 200 g.kg ${ }^{-1}$, nos dias 04, 12 e 18 DEZ 1995, para o controle, principalmente da antracnose dos feijoeiros. O EM, nas diferentes diluições, foi aplicado diretamente sobre as plantas em 27 NOV 1995, 04, 12 e 18 DEZ 1995, 02 e 06 JAN 1996 e 09 FEV 1996, ou seja, primeiro com espaço de tempo semanal, em seguida quinzenal e finalmente mensal. Em 02 FEV 1996, aos setenta dias de ciclo, foram coletadas amostras de cinco plantas para análise morfológica das plantas. Imediatamente antes da colheita realizada no dia 23 FEV 1996, foi contada a população final e feita a amostragem de dez plantas para estimativa dos componentes do rendimento dos feijoeiros. Foi utilizada a variedade de feijão FT 120, que tem sementes de cor preta, hábito de crescimento indeterminado e porte ereto (IAPAR, 1992). No segundo ano, em 29 AGO 1996, foi feita a aração e duas gradagens niveladoras. Antes da segunda gradagem aplicou-se herbicida com o princípio ativo trifluralin, para o controle das plantas daninhas encontradas, principalmente gramíneas anuais, muito freqüentes na área. Em 16 SET 1996 foi distribuída e incorporada com enxada silagem de milho nas parcelas que receberiam o EM, na base de 20 t.ha $^{-1}$, com a

Quadro 1. Características químicas e físicas do solo Latossolo Vermelho Amarelo Álico da área dos experimentos, na Estação Experimental do Canguiri, CEEx, UFPR. Pinhais, PR. 1995/97. ${ }^{1}$

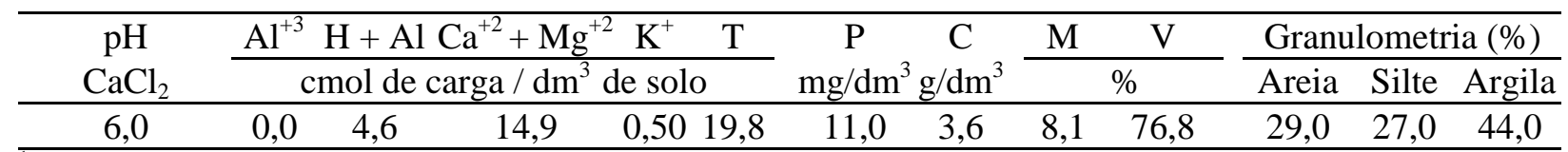

${ }^{1}$ Análises realizadas no Laboratório de Análises de Solos do Departamento de Solos da UFPR.

finalidade de servir como fonte de matéria orgânica para melhor ação do produto. Em 14 OUT 1996 foram feitos, com enxada, os sulcos para adubação e semeadura manuais. As parcelas a serem adubadas com adubo químico receberam o equivalente a $300 \mathrm{~kg} \cdot \mathrm{ha}^{-1}$ do formulado NPK 4-30-10, que foi misturado ao solo. Quatorze dias após a emergência das plantas, em 05 NOV 1996, foi feita, nessas parcelas, a adubação em cobertura com $\mathrm{N}$ na proporção de $40 \mathrm{~kg} \cdot \mathrm{ha}^{-1}$, utilizando-se a uréia como fonte. As sementes foram previamente tratadas com fungicida a base de benomil e colocadas no sulco em quantidade suficiente para obter população de aproximadamente trezentas mil plantas por hectare. A emergência da cultura foi uniforme, identificada em 22 OUT 1996 e em 25 OUT 1996 foi feita a 
contagem da população inicial. Em 28 OUT 1996 foi feita a primeira capina com enxada e a segunda em 20 NOV 1996. Durante o ciclo foram feitas três aplicações com o fungicida a base da mistura de clorotalonil, $500 \mathrm{~g} \cdot \mathrm{kg}^{-1}+$ tiofanato metílico, $200 \mathrm{~g} \cdot \mathrm{kg}^{-1}$, nos dias 07, 14 e 21 NOV 1996, para o controle, principalmente da antracnose dos feijoeiros. O $\mathrm{EM}$, nas diferentes diluições, foi aplicado diretamente sobre as plantas em 25 OUT 1996, 01, 08, 14 e 29 NOV 1996, 13 DEZ 1996 e 13 JAN 1997, ou seja, primeiro com espaço de tempo semanal, em seguida quinzenal e finalmente mensal. Imediatamente antes da colheita realizada no dia $26 \mathrm{JAN} 1997$, foi contada a população final e feita a amostragem de dez plantas para estimativa dos componentes do rendimento dos feijoeiros. Foi utilizada a variedade de feijão FT NOBRE, que tem sementes de cor preta, hábito de crescimento indeterminado e porte ereto (FT Pesquisa e Sementes, 1996).

Utilizou-se o delineamento experimental em blocos ao acaso com quatro repetições. Os tratamentos testados foram oito. Seis deles com diferentes diluições de EM (1:250, 1:500, 1:750, 1:1.000, 1:1.250 E 1:1.500), um com adubação química NPK e um como testemunha sem adubação. A área total do experimento foi de $24,0 \mathrm{~m} \times 18,0 \mathrm{~m}=432,0 \mathrm{~m}^{2}$. Cada um dos quatro blocos tinha $8,0 \mathrm{mx} 11,0 \mathrm{~m}=88,0 \mathrm{~m}^{2} \mathrm{e}$ cada parcela ou unidade experimental tinha $2,0 \mathrm{~m} \times 5,0 \mathrm{~m}=10,0 \mathrm{~m}^{2}$. As parcelas eram compostas de quatro fileiras de $5,0 \mathrm{~m}$ de comprimento. Destas as duas centrais, descontados $0,50 \mathrm{~m}$ em cada extremidade, foram utilizadas como área útil, ou seja, $1,0 \mathrm{~m} \times 4,0 \mathrm{~m}=4,0 \mathrm{~m}^{2}$, para todas as avaliações feitas. As avaliações feitas, foram a estimativa das populações inicial e final por meio da contagem do número de plantas, respectivamente no quinto dia após a emergência, (Estádio $V_{2}=$ Folhas primárias completamente abertas) e imediatamente antes da colheita (Estádio $\mathrm{R}_{9}=$ Maturação); a estimativa do comportamento morfológico das plantas, feita apenas no primeiro ano agrícola, mediante a amostragem de cinco delas, aos setenta dias após a emergência (Estádio $\mathrm{R}_{8}=$ Enchimento de vagens), sendo feitas as medidas da altura das plantas e do diâmetro do caule ou haste principal e a contagem dos números de nós da haste principal e de folhas trifolioladas totais, a estimativa dos componentes do rendimento, por meio da colheita, em separado, de dez plantas, no estádio $\mathrm{R}_{9}$, para as contagens dos números totais de vagens e sementes, que permitiram, respectivamente, estimar os números médios de vagens por planta e de sementes por vagem e, ainda, determinação do peso médio de cem sementes em três amostras; e a estimativa do rendimento por meio do peso das sementes produzidas por parcela (Fernández et al.). Os resultados das diferentes avaliações foram submetidos a análise de variância. As variâncias foram avaliadas pelo teste de Bartlett quanto a homogeneidade. As variáveis cujas variâncias foram homogêneas tiveram os tratamentos avaliados pelo teste de F. Quando os resultados revelaram significância, nos níveis de 5\% e $1 \%$ de probabilidade, as médias foram comparadas pelo teste de Tukey no nível de $5 \%$ de probabilidade (Gomes, 1970; Steel \& Torrie, 1960).

\section{RESULTADOS E DISCUSSÃO}

Os resultados obtidos no primeiro ano agrícola, 1995/96, das avaliações das características morfológicas, altura média de plantas, diâmetro médio do caule, número médio de folhas trifolioladas e número médio de nós, são apresentados pelo Quadro 2 e os das populações inicial e final, dos componentes do rendimento e do rendimento propriamente dito, pelo Quadro 3 e os do segundo ano agrícola, 1996/97, referentes às populações inicial e final, aos componentes do rendimento e ao rendimento, pelo Quadro 4.

Observa-se, pelo Quadro 2, que no ano agrícola 1995/96, das características morfológicas analisadas, apenas o número médio de folhas trifolioladas mostrou diferenças significativas entre os tratamentos. No entanto, essas diferenças foram apenas entre as doses do EM. Aparentemente, o aumento na concentração do produto tende a ser prejudicial, porém, não 
houve consistência para a proporcionalidade inversa entre doses e número de folhas.

Observa-se, pelo Quadro 3, que para o ano agrícola 1995/96, os tratamentos não tiveram qualquer influência sobre a população de plantas. Quanto a população inicial isso era esperado, uma vez que a semeadura foi feita considerando percentagem de germinação e vigor das sementes, portanto, o esperado era que a população fosse próxima de trezentas mil plantas. Isso ocorreu inclusive no tratamento sem qualquer adubação. Quanto a população final as reduções encontradas, de aproximadamente $10 \%$, estão dentro do esperado e, efetivamente, não interferiram nos resultados (Vieira, 1978). Entre os componentes do rendimento, apenas o número médio de vagens por planta foi influenciado, significativamente, pelos tratamentos. Isso confirma observações feitas em outros trabalhos que identificaram esse componente como o que melhor representa o rendimento (Duarte \& Adams, 1972; Santos et al., 1982). De qualquer modo, a influência não é consistente com o aumento das doses do EM, mesmo sendo as doses mais elevadas as que produziram os melhores resultados com o produto, porém, não diferentes do resultado obtido com o tratamento tradicional com adubação química NPK. Situação muito semelhante pode ser observada para a avaliação do rendimento. $\mathrm{O}$ melhor resultado foi obtido com o tratamento tradicional com adubação química NPK havendo dois tratamentos com EM que foram, estatisticamente iguais, porém, não há qualquer tendência de dose melhor, contrariando inclusive semelhanças a serem esperadas com o número médio de vagens por planta e confirmando a inconsistência referida para a característica morfológica número médio de folhas trifolioladas discutida anteriormente. $\mathrm{O}$ ano agrícola foi muito chuvoso, $835,40 \mathrm{~mm}$ durante o ciclo da cultura, quando o esperado e desejado seria entre 300 e $400 \mathrm{~mm}$ (IAPAR, 1989), provavelmente em razão do excesso de umidade e da presença de temperaturas mais amenas, condições ideais para o desenvolvimento do fungo da antracnose, tenha ocorrido incidência tão grande desse patógeno, mesmo com o controle fitossanitário descrito. Isso levou a redução na produtividade dos feijoeiros que apresentaram rendimentos que podem ser considerados muito ruins para trabalhos experimentais.

No ano agrícola 1996/97 não foram feitas as avaliações do comportamento morfológico das plantas. Observa-se, pelo Quadro 4, que neste ano agrícola, a semelhança do que havia ocorrido no ano anterior, os tratamentos não tiveram qualquer influência sobre a população de plantas.

Nota-se que a população inicial foi aproximadamente $10 \%$ menor que a do primeiro ano, em razão de ataque por fungo do solo, mesmo tendo sido feito o tratamento das sementes. A diferença entre as populações inicial e final foi, em média, $6 \%$, também dentro do esperado (Vieira, 1978), sem interferência nos resultados. Não houve destaques entre os componentes do rendimento. As médias do rendimento, neste ano agrícola mais favorável e com menor influência da antracnose foram, certamente, melhores que as do ano agrícola anterior. Observou-se que o tratamento tradicional com adubação química NPK foi, sem dúvida, o melhor de todos, cerca de $21 \%$ superior ao segundo em produtividade que foi o tratamento testemunha sem adubação. Os tratamentos com o EM repetiram a instabilidade observada no ano anterior. Não foi possível identificar qualquer tipo de tendência que se repetisse para recomendação de dose. Neste caso os resultados obtidos discordam dos obtidos por Higa, 1991a ; Higa, 1991b e Fundação Mokiti Okada, 1994. 
Quadro 2. Resultados das avaliações das características morfológicas. Pinhais, PR. 1995/96.

\begin{tabular}{|c|c|c|c|c|}
\hline Tratamentos $^{1}$ & $\begin{array}{c}\text { Altura média } \\
\text { de plantas } \\
(\mathrm{cm})\end{array}$ & $\begin{array}{c}\text { Diâmetro médio } \\
\text { do caule } \\
(\mathrm{mm})\end{array}$ & $\begin{array}{c}\text { Número médio } \\
\text { de folhas } \\
\text { trifolioladas } \\
\end{array}$ & $\begin{array}{l}\text { Número } \\
\text { médio } \\
\text { de nós } \\
\end{array}$ \\
\hline 1. $\operatorname{EM}(1: 250)$ & 55,5 & 5,8 & $14,1 \mathrm{a}$ & 14,4 \\
\hline 2. $\operatorname{EM}(1: 500)$ & 45,7 & 5,1 & $11,3 \mathrm{ab}$ & 13,0 \\
\hline 3. EM (1:750) & 42,4 & 5,2 & $10,8 \mathrm{~b}$ & 11,6 \\
\hline 4. $\operatorname{EM}(1: 1.000)$ & 47,7 & 5,6 & $10,2 \mathrm{~b}$ & 13,0 \\
\hline 5. EM $(1: 1.250)$ & 47,5 & 5,6 & $12,0 \mathrm{ab}$ & 13,2 \\
\hline 6. $\operatorname{EM}(1: 1.500)$ & 49,2 & 5,5 & $9,7 \mathrm{~b}$ & 12,6 \\
\hline 7. NPK & 56,8 & 6,0 & $11,2 \mathrm{ab}$ & 13,8 \\
\hline 8. Testemunha sem adubação & 52,8 & 5,4 & $11,2 \mathrm{ab}$ & 14,5 \\
\hline F de tratamentos & $2,2^{\mathrm{ns}}$ & $1,33^{\mathrm{ns}}$ & $4,89 * *$ & $2,34^{\mathrm{ns}}$ \\
\hline $\mathrm{CV}(\%)$ & 13,50 & 9,50 & 10,60 & 9,46 \\
\hline \multicolumn{5}{|c|}{$\begin{array}{l}\text { EM = Microrganismos eficazes. CV = Coeficiente de variação. } \\
2 \text { Médias seguidas pelas mesmas letras, na vertical, não diferem significativamente, pelo teste de Tukey, ao níve } \\
\text { de } 5 \% \text { de probabilidade. } \\
\text { ** Significativo ao nível de } 1 \% \text { de probabilidade. } \\
\text { ns Não significativo. }\end{array}$} \\
\hline
\end{tabular}

Quadro 3 - Resultados das avaliações de população, componentes do rendimento e rendimento. Pinhais, PR. $1995 / 96$.

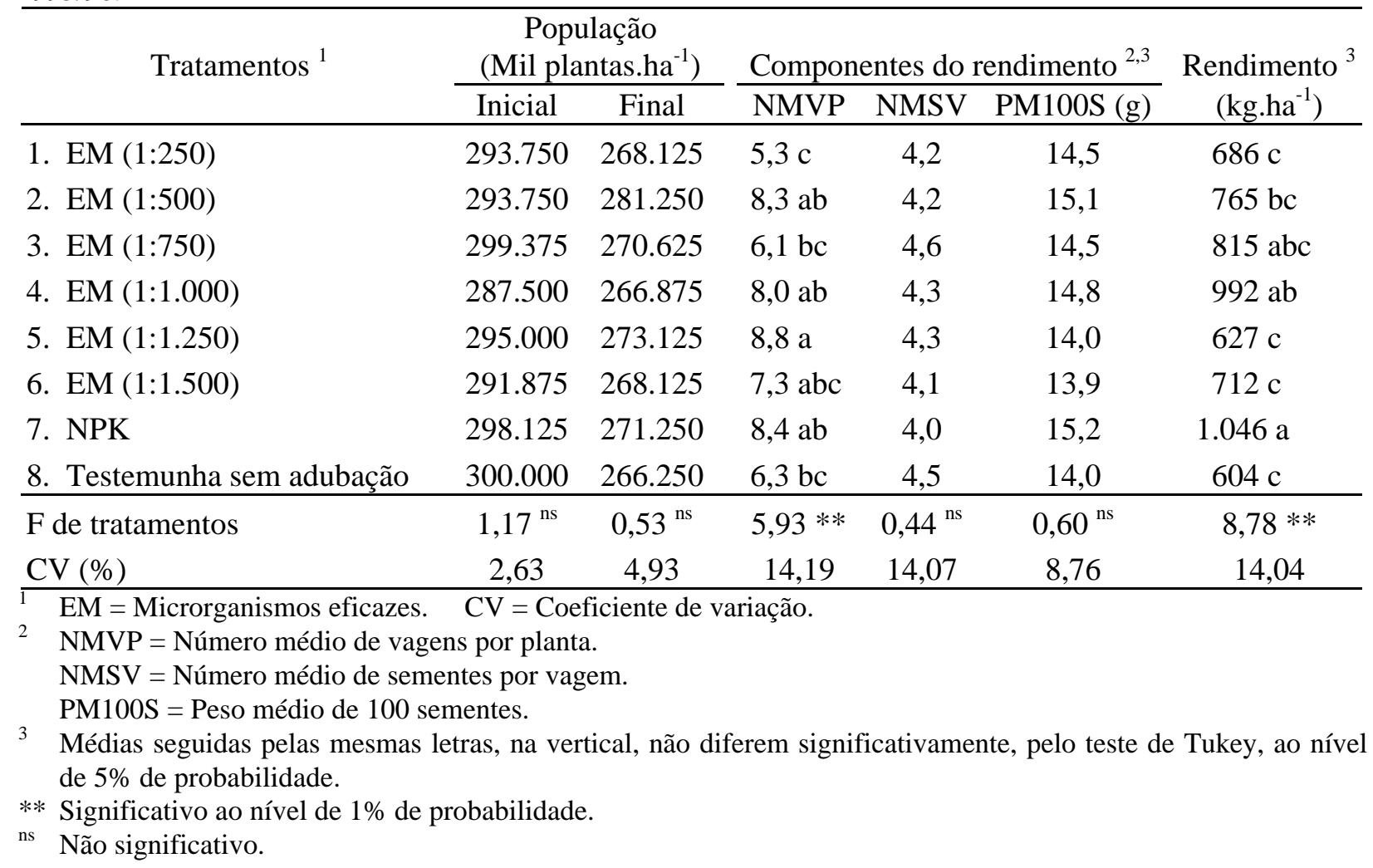


Quadro 4. Resultados das avaliações de população, componentes do rendimento e rendimento. Pinhais, PR. 1996/97.

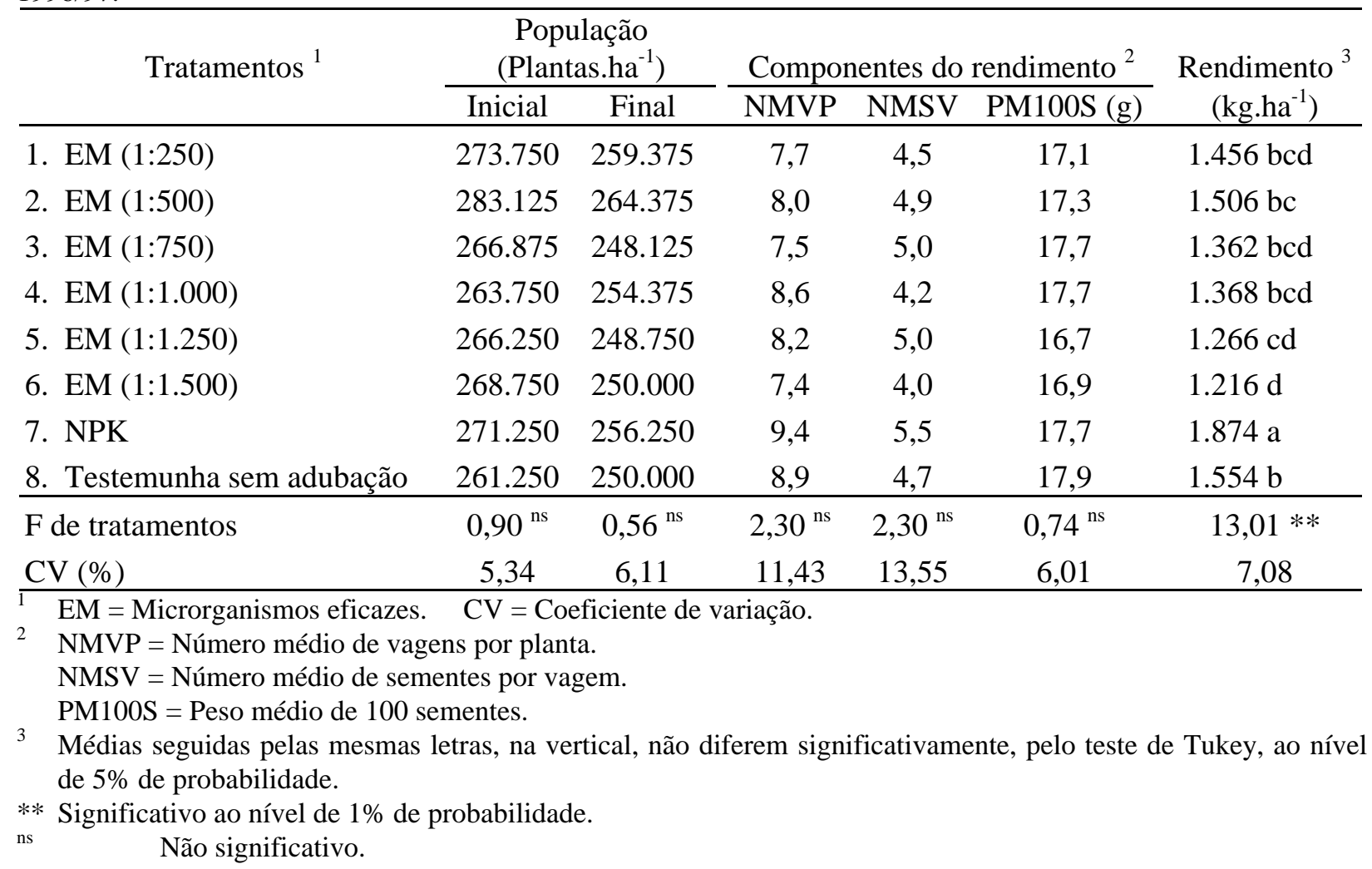

\section{CONCLUSÕES}

Considerando as condições em que os experimentos foram conduzidos pode-se concluir que o produto $\mathrm{EM}$ não mostrou consistência nos resultados que justificasse sua recomendação como substituto da adubação química NPK tradicional e que não foram encontradas evidências para indicar a utilização de qualquer das diluições do produto.

\section{AGRADECIMENTOS}

Os autores agradecem a colaboração eficiente do sr. Rainério Ferrarini na execução dos trabalhos de campo.

\section{RESUMO}

Em razão da importância do feijão como alimento e da necessidade de produzir mais dessa fabácea (leguminosa) foram conduzidos dois experimentos, nos anos agrícolas de 1995/96 e 1996/97, para avaliar a ação fertilizante do produto microrganismos eficazes (EM) em comparação com a adubação química NPK tradicional. O trabalho experimental foi realizado na Universidade Federal do Paraná Estação Experimental do Canguiri, em Pinhais, PR, em área uniforme com solo caracterizado como Latossolo Vermelho Amarelo Álico. O preparo do solo foi o convencional com aração e gradagens. O EM foi testado em seis diluições, $1: 250,1: 500,1: 750,1: 1.000,1: 1.250$ e 1:1.500. As aplicações do produto foram sempre sobre as folhas das plantas e em sete épocas, para todas as diluições, quatro semanais, duas quinzenais e uma mensal. $O$ tratamento com a adubação química NPK foi definido de acordo com a análise química do solo e colocado no sulco de semeadura sendo complementado por adubação em cobertura com nitrogênio. $\mathrm{O}$ delineamento experimental utilizado foi o de blocos ao acaso com quatro repetições. Foram avaliadas, apenas no primeiro ano agrícola, as características morfológicas, altura média de plantas, diâmetro médio do caule ou haste principal, número 
médio de nós na haste principal e número médio de folhas trifolioladas e nos dois anos agrícolas, as populações inicial e final, os componentes do rendimento e o rendimento. Os resultados obtidos mostraram que nas condições em que os experimentos foram conduzidos o produto EM não deve ser recomendado como substituto da adubação química NPK tradicional, não tendo sido encontradas evidências para indicar a utilização de qualquer das diluições do produto.

\section{REFERÊNCIAS BIBLIOGRÁFICAS}

Demarchi, M. Feijão. Acompanhamento da Situação Agropecuária do Paraná, Curitiba, 23(9):17-24. 1997. (Prognóstico Safra 97/98)

Duarte, R. A. \& Adams, M. W. A path coefficient analysis of some yield component interrelations in field beans (Phaseolus vulgaris L.). Crop Science, Madison, 12(5):579-582. 1972.

Fernández, F.; Gepts, P. \& López-G., M. Etapas de desarrollo de la planta de fríjol común. Cali, CIAT, 1982. 26p. (Guia de estudio)

FT Pesquisa e Sementes. Recomendações de cultivo. Ponta Grossa, FT Pesquisa e Sementes, 1995. 52p.

Fundação Mokiti Okada. Manual sobre o uso do EM na agricultura. São Paulo, Fundação Mokiti Okada, s/d. 8p.

Fundação Mokiti Okada. III Encontro de Produtores da Agricultura Natural Messiânica. São Paulo, Fundação Mokiti Okada, 1994. 23p.

Gomes, F. P. Curso de estatística experimental. 4.ed. Piracicaba, Nobel, 1970. 468p.

Higa, T. Utilization of microorganism for agriculture and conservation of environment. Rokio, Nosan Gyoson Bunka Kiokai, 1991. $216 \mathrm{p}$.

Higa, T. Agricultura natural a solução do problema alimentar. São Paulo, Fundação Mokiti Okada, 1991. 40p.

IAPAR - Instituto Agronômico do Paraná. O feijão no Paraná. Londrina, IAPAR, 1989. 303. (Circular 63)

IAPAR - Instituto Agronômico do Paraná. IAPAR 20 anos: Cultivares para o Paraná. Londrina, IAPAR, 1992. 140p.

IBGE - Instituto Brasileiro de Geografia e Estatística. Anuário estatístico do Brasil.
Rio de Janeiro, IBGE, 1996. p.1-1 a 8-325 (v.56)

Malavolta, E. (Coord.) Nutrição e adubação. In: Simpósio Brasileiro de Feijão, 1, Campinas, 1971. Anais. Viçosa, UFV, 1972. p.209-242.

Moraes, J. F. V. Calagem e adubação. In: Zimmermann, M. J. O.; Rocha, M. \& Yamada, T. Cultura do feijoeiro: fatores que afetam a produtividade. Piracicaba, POTAFOS, 1988. p.261-301

Melloni, R.; Duarte, K, M. R. \& Cardoso, E. J. B. N. Efeito de composto de lixo urbano e EM (microrganismos eficientes) no controle de fusariose e no desenvolvimento vegetativo de pepino. In: Reunião Brasileira sobre Controle Biológico de Doenças de Plantas, IV, Campinas, 1991. Anais. Campinas, EMBRAPA-CNPDA, 1991. p.17.

Oliveira, I. P.; Araújo, R. S. \& Dutra, L. G. Nutrição mineral e fixação biológica de nitrogênio. In: Araújo, R. S.; Rava, C. A.; Stone, L. F. \& Zimmermann, M. J. O. (Coord.) Cultura do feijoeiro comum no Brasil. Piracicaba, POTAFOS, 1996. p.170221

Santos, J. B.; Vello, N. A. \& Ramalho, M. A. P. Stability of grain yield and of its basic components in beans (Phaseolus vulgaris L.). Revista Brasileira de Genética, São Paulo, 5(4):761-772. 1982.

Thung, M. Bean agronomy in monoculture. In: Schoonhoven, A. \& Voysest, O. (Ed.) Common beans: research for crop improvement. Wallingford, CAB International, 1991. p.737-834

Vieira, C. Cultura do feijão. Viçosa, UFV, 1978. $146 \mathrm{p}$.

Vilhordo, B. W. Feijão, aspectos nutricionais. IPAGRO Informa, Porto Alegre, 30:7-8. 1988.

Vogtman, H. \& Wagner, R. Agricultura ecológica: Teoria e prática. Porto Alegre, Mercado Aberto, 1987. 164p.

Yokoyama, L. P.; Kossel, B. \& Kluthcouski, J. Aspectos sócio econômicos da cultura. In: Araújo, R. S.; Rava, C. A.; Stone, L. F. \& Zimmermann, M. J. O. (Coord.) Cultura do feijoeiro comum no Brasil. Piracicaba, POTAFOS, 1996. p.1-21 